\title{
Preface
}

This book embraces a vision of deviance as a set of social processes involving a wide range of social dynamics and influences, including the multiple influences on human behavior emphasized by many positivistic theories of deviant behavior. The overarching approach of the book, however, is fully grounded in symbolic interactionism. Among the analytic approaches to deviance, only symbolic interactionism (or social construction, as some prefer) moves beyond the limited question of "what causes deviant behavior?" As valuable as the answers to that question can be, focusing solely on the causes of deviant behavior can give the inaccurate impression that what is defined as deviant behavior is always and everywhere the same. But while all human cultures have made distinctions between good and bad acts, what has been considered good or bad has varied widely. Definitions of deviance are far from universal, even within most societies at any given point in time. Focusing exclusively on the causes of deviant behavior misses more of the deviance process than it captures.

\section{THE DEVIANCE PROCESS}

Symbolic interactionism has been critical to the study of deviance since the early 1960s, but in the 1970 s popular interpretations of interactionist contributions to the study of deviance focused overwhelmingly on labeling theory. The core insight of labeling theory was the idea that being identified and treated as deviant often leads to increased deviant behavior and role engulfment in a deviant identity. The social contexts in which that insight holds remains an important empirical question, but it is only a piece of what symbolic interaction has to offer to the study of deviance. This book provides instructors and students with a broader interactionist/constructionist analysis of the deviance process, focused on (1) activities of moral entrepreneurs who seek to define certain behaviors and statuses as deviant, (2) thoughts and actions of rule-breakers who knowingly or unknowingly violate the rules, (3) social control efforts focused on identifying and sanctioning or treating rule-breakers, and (4) the responses of rule-breakers to the formal and informal social control efforts directed at them.

\section{Moral Entrepreneurship}

The term "moral entrepreneur" was created by Howard Becker in his 1963 study of the Federal Bureau of Narcotics campaign to define marijuana as harmful and its users as evil. Scholars have found the concept useful for examining the social construction of what Stanley Cohen (1973) terms "moral panics" related to a wide range of deviance categories. Analysis focused on the creation and dissemination of "atrocity tales" (Bromley et al. 1979) has provided an additional vantage point to assess the narrative similarities underlying the creation of moral panics related to a wide range of deviance categories. Finally, David Snow and colleagues' 
(Snow et al. 1986a; Snow and Benford 1988) studies of "framing processes" have provided additional concepts for analyzing deviance that link moral entrepreneurship to social movements, medical discourse, and popular culture.

\section{Rule-Breaking}

Rule-breaking has always been a central focus of deviance studies, both from positivistic and interpretive perspectives. While positivistic theories seek explanations for rule-breaking that are external to, or at least largely beyond the control of, those who violate social norms, symbolic interactionism gives voice to the experiences and identities of those who are defined as deviant. Ethnographic research can be valuable in all fields of sociological inquiry, but it is especially critical when seeking to understand the experiences of those who consciously violate social norms. This contribution of symbolic interactionism and ethnographic research is a staple of deviance textbooks. This book continues the tradition of drawing on deviance ethnographies to share "deviants" voices in their own words. But rather than relying mostly on classic past studies, I have mined the wealth of recent ethnographies for up-to-date descriptions of deviants' experiences and voices.

\section{Social Control}

The interactionist/constructionist approach to the deviance process recognizes that normative violations are embedded in broader social contexts that gain particular salience when individuals are identified and treated as rule-breakers. At that point, people who are identified as "deviants" find themselves subject to formal and informal sanctions and treatment. Often, they are pulled into organizational processing through the criminal justice system or medicalized treatment programs. The societal responses to those identified as specific types of deviants change over time, typically in tandem with changing definitions of the causes and consequences of deviant behavior. But both labeling and treating of "deviants" can vary enormously based on race, class, and gender. This book draws upon both quantitative and qualitative research to discuss current societal responses and biases in punishment and treatment of different kinds of deviants.

\section{Stigma Management and Resistance}

Those identified as deviant seldom passively accept stigmatizing labels and the punitive treatment directed toward them. Instead, they engage in a range of stigma management activities: passing as nondeviant, seeking to minimize the perception of their deviance, embracing recovery, and even at times turning the alleged deviance into a source of pride and power. The options available for resistance and stigma management vary across deviance categories and over time, frequently with race, class, and gender differences.

The deviance process is multifaceted and seldom static for long. What was acceptable and/or legal at one point in time (regular opiate use or prostitution) becomes unacceptable and illegal. What was illegal (use of contraceptives) or considered mental illness (homosexuality) becomes widely accepted. As of this writing, "pot" is (or soon will be) legally sold for recreational use in eight states, while in many adjacent states and at the federal level selling marijuana is a felony. Prison populations soar, leading even conservative politicians to question mandatory sentencing practices. And the Internet provides venues for both moral entrepreneurship and resistance. The symbolic interactionist/constructionist perspective outlined above provides an analytic framework for understanding deviance as a continually recursive process. 


\section{ORGANIZATION}

This book is divided into four sections. Section 1 introduces students to the field of deviance studies, comparing empirical sociological study of deviance to popular cultural conceptions of deviant behavior as rooted in evil, illness, or relativistic cultural differences. Chapter 2 highlights sociology's commitment to empirical research, with particular emphasis on the value of ethnographic research for studying deviance. Chapter 3 examines positivistic theories of deviant behavior and Chapter 4 presents the symbolic interactionist perspective that will be used in each of the substantive chapters. The following three sections of the book focus on specific common deviance categories.

Section 2 provides an analysis of several kinds of criminal deviance that involve unwilling victims: murder, rape, street-level property crime, and white-collar crime. These forms of deviance (or at least the first three) represent types of deviance characterized by high public consensus and formal legal sanctions. Virtually all societies consider certain kinds of killing, sexual coercion, and property crime as reprehensible acts. And yet, what counts as murder, rape, or robbery varies significantly from one culture to another and even within the United States over time.

Section 3 examines three types of what is often termed "lifestyle deviance." These deviance categories are characterized by significantly less public consensus concerning their harmfulness to individuals and society as well as greatly increased subcultural proliferation. Participants often justify these kinds of deviance by assertions of legitimate lifestyle choice-of individual rights and the lack of a victim-claims that moral entrepreneurs strongly contest.

Section 4 examines a set of deviance categories often referred to as "status deviance." People in these categories are considered deviant by virtue of negatively evaluated and largely invol- untary statuses, conditions, or identities that they have (e.g., illnesses, physical defects, alternative sexual orientations and gender identities, etc.). While status deviance categories involve the same social processes as other deviance categories, they exhibit more deviant identity transformation and collective action associated with positive conceptions of those associated with the deviance category.

The chapters in Sections 2 through 4 follow a uniform organization in order to provide students with consistency across chapters and reinforcement of key concepts and issues.

\section{PEDAGOGICAL FEATURES}

Three pedagogical features of this book warrant brief discussion. First, each chapter includes two Blurred Boundary sections, one at the start of the chapter and the other at chapter end. The term Blurred Boundaries is used throughout this book to refer to (1) the often hazy distinctions between what is considered moral versus immoral, or good as opposed to bad, (2) the confusion that results from conflicting and often overlapping explanations that are given to explain why people engage in deviant behavior, and (3) the challenges of developing social policies to address social harm while respecting human rights. The Blurred Boundaries theme is integrated throughout the text, challenging students to move beyond black-and-white, kneejerk reactions and to engage in thoughtful assessments of deviance categories and social policies.

Second, each chapter includes an optional mini-research project titled Pushing Your Boundaries that asks students to collect and/or briefly analyze some "data" that are relevant to specific course topics. These assignments, which have been field-tested in several classes, help students see connections between the 
course and the world beyond the classroom and reinforce the importance of empirical research.

Third, all chapters (except the introduction) include a short Claims-Maker Profile of an individual (or couple) who has been a notable advocate for particular claims-either in defining deviance or responding to it. Chapters in the first section of the book profile exemplary deviance scholars, while chapters in the rest of the book profile people who have played significant roles in social policy or social action related to the chapter's topic. The profiles connect personal faces and memorable stories to chapter topics, illustrating the importance of engaged social action.

\section{SUPPLEMENTAL MATERIALS}

The Instructor's Manual includes chapter outlines; Power Point lectures; a test bank with essay, short-answer, and multiple-choice questions; and suggested video and Internet resources for each chapter. The Instructor's Manual also provides suggested student Blackboard/WebCT discussion group topics and exercises for instructors who want to use web-based pedagogy.

\section{ACKNOWLEDGMENTS}

This book has been a long time in coming. I want to thank Chris Caldeira and Thomas Vander Ven for their early enthusiasm and support for the project. Seth Dobrin and Nic Albert at the University of California Press have given me critical guidance for bringing the book to completion. Matthew Austin provided teaching assistance the first time I taught the course using these materials at Ohio University. Stephen Van Geem at Utah State University took the plunge early and taught with previous versions of the manuscript, providing feedback along the way. Kenny Chumbley provided excellent support with graphics and permissions. Over a dozen anonymous reviewers have read versions of the manuscript and given sage advice on how it could be improved. My gratitude to you all.

This project has been bookended by a sabbatical at Ohio University where I began the book and a sabbatical at Utah State University where I have completed it.

I want to thank my wife, Kate, especially, for her consistent encouragement and for never losing faith in the project-or my ability to pull it off.

Finally, this textbook is only possible because countless scholars in the social sciences and humanities have found the interactionist/ constructionist approach valuable in their research. I am indebted to all whose work I draw upon. This is a collective effort and I hope I have done your work close to the justice it deserves. 